\title{
Tracer-aided modelling reveals quick runoff generation and groundwater losses producing young streamflow ages in a tropical rainforest catchment
}

\author{
Leia Mayer-Anhalt ${ }^{1}$, Christian Birkel ${ }^{2}$, Ricardo Sanchez-Murillo ${ }^{3}$, and Stephan Schulz ${ }^{4}$ \\ ${ }^{1}$ Technical University of Darmstadt Institute of Applied Geosciences \\ ${ }^{2}$ University of Costa Rica \\ ${ }^{3}$ Universidad Nacional de Costa Rica \\ ${ }^{4}$ Technische Universität Darmstadt
}

May 29, 2021

\begin{abstract}
There is still limited understanding of how waters mix, where waters come from and for how long they reside in tropical catchments. In this study, we used a tracer-aided model (TAM) and a gamma convolution integral model (GM) to assess runoff generation, mixing processes, water ages and transit times (TT) in the pristine humid tropical rainforest Quebrada Grande catchment in central Costa Rica. Models are based on a four-year data record (2016 to 2019) of continuous hydrometric and stable isotope observations. Both models agreed on a young water component of fewer than 95 days in age for $75 \%$ of the study period. The streamflow water ages ranged from around two months for wetter years (2017) and up to 9.5 months for drier (2019) years with a better agreement between the GM estimated TTs and TAM water ages for younger waters. Such short TTs and water ages result from high annual rainfall volumes even during drier years with 4,300 mm of annual precipitation (2019) indicating consistent quick near-surface runoff generation with limited mixing of waters and a supra-regional groundwater flow of likely unmeasured older waters. The TAM in addition to the GM allowed simulating streamflow (KGE > 0.78), suggesting an average groundwater contribution of less than $40 \%$ to streamflow. The model parameter uncertainty was constrained in calibration using stable water isotopes $\left(\delta^{2} \mathrm{H}\right)$, justifying the higher TAM model parameterization. We conclude that the multimodel analysis provided consistent water age estimates of a young water dominated catchment. This study represents an outlier compared to the globally predominant old water paradox, exhibiting a tropical rainforest catchment with higher new water fractions than older water.
\end{abstract}

\section{Hosted file}

Dantas tracer-aided modelling paper final.docx available at https://authorea.com/users/ 416588/articles/524069-tracer-aided-modelling-reveals-quick-runoff-generation-andgroundwater-losses-producing-young-streamflow-ages-in-a-tropical-rainforest-catchment 

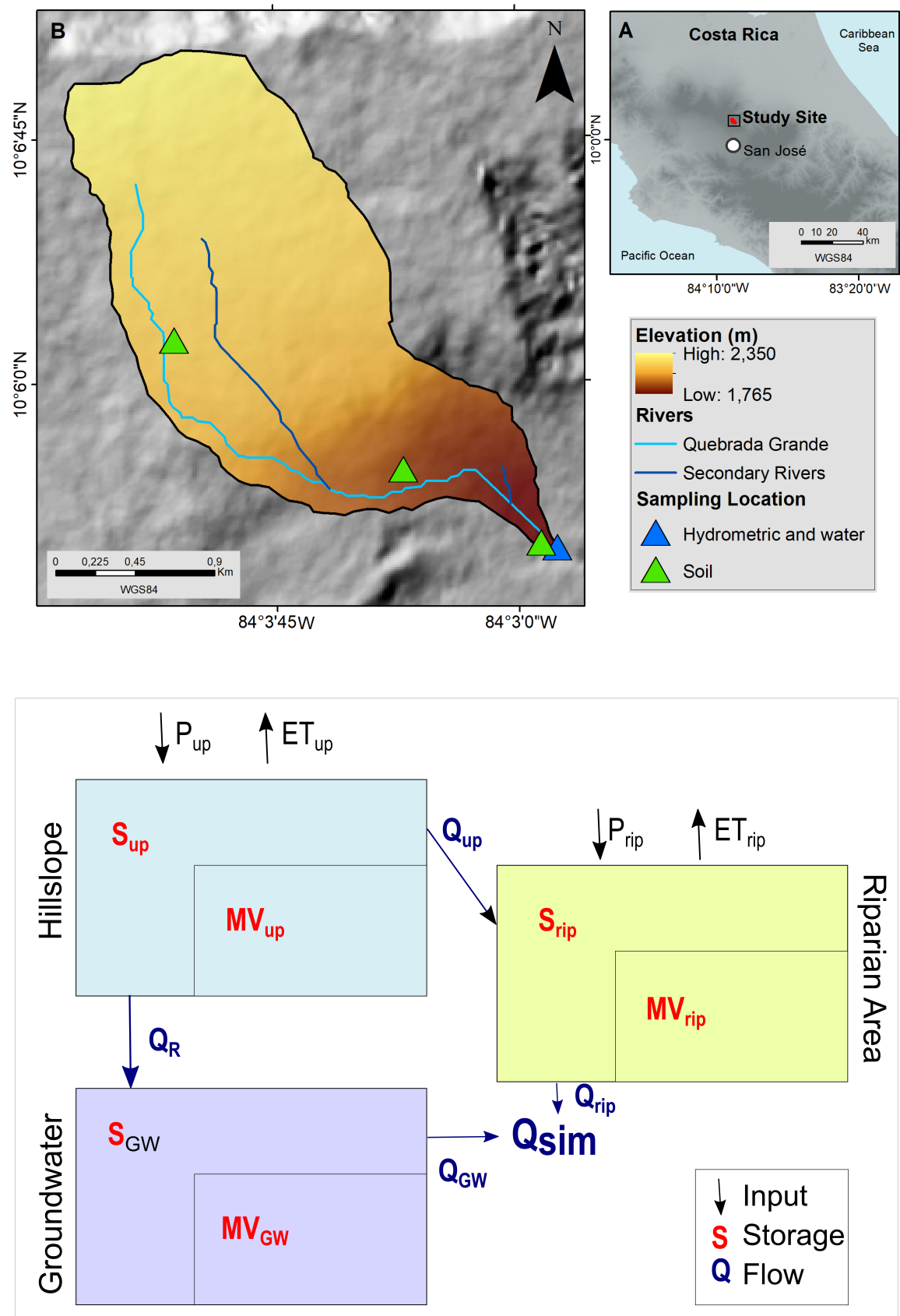

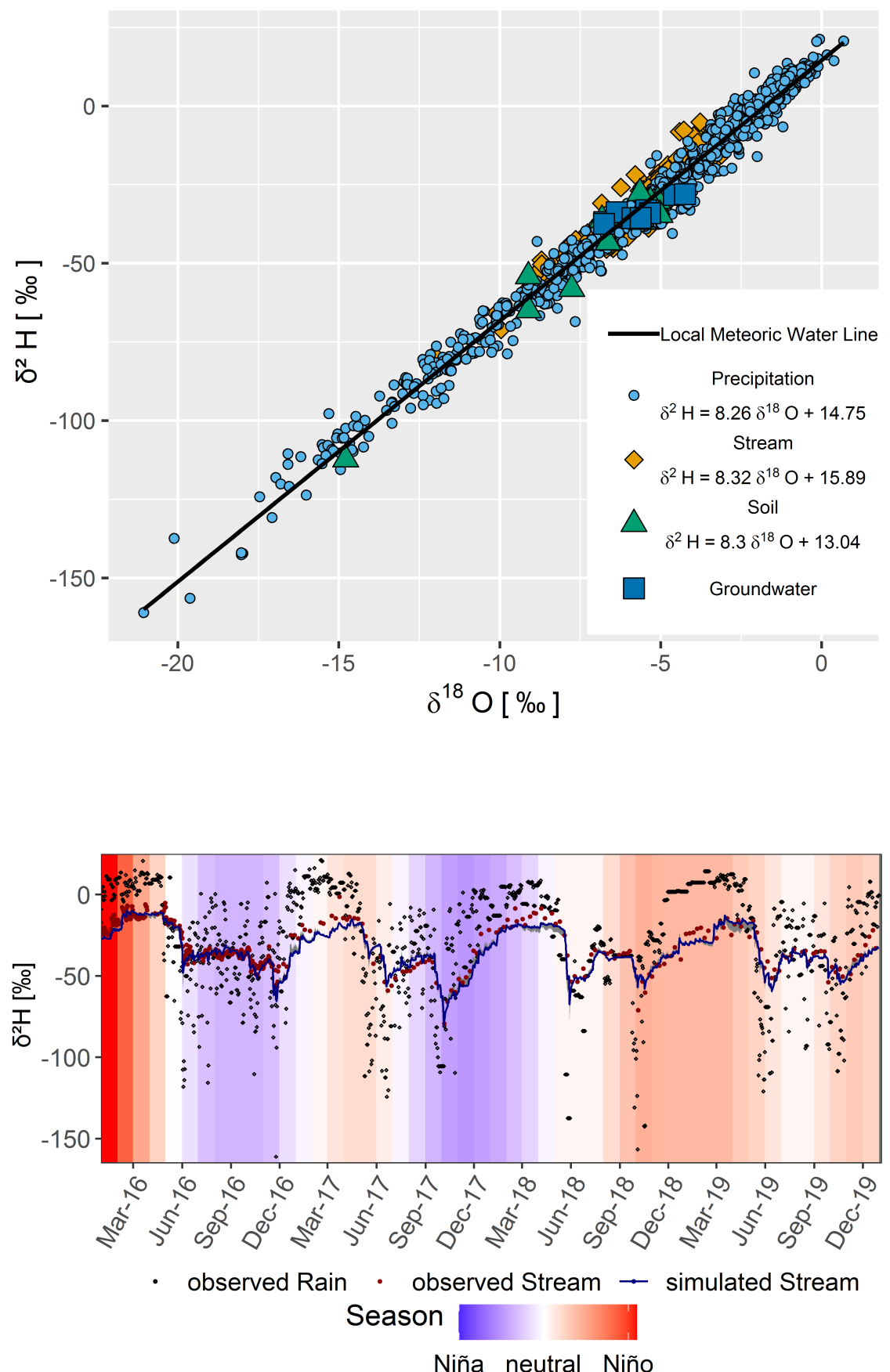


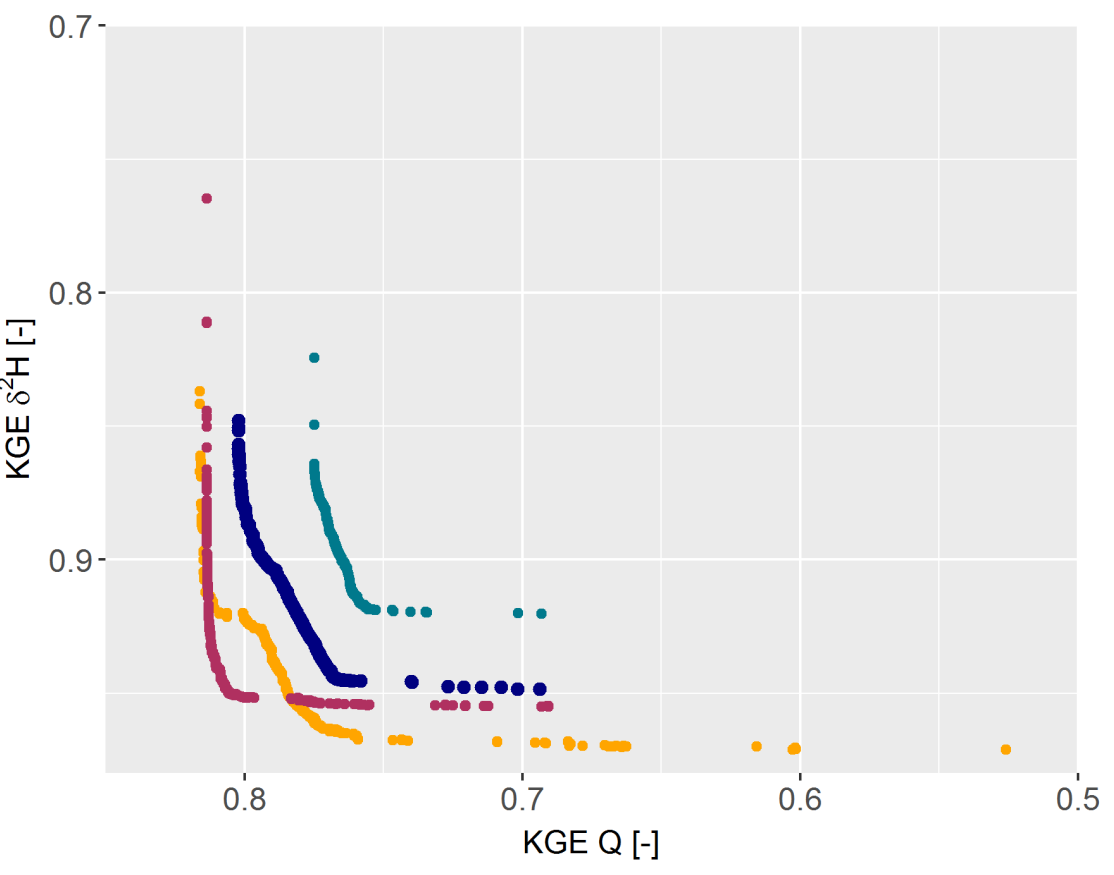

Calibration • 2017-2019 • 2017 • 2018 • 2019

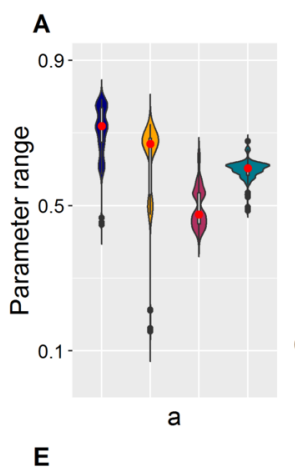

B
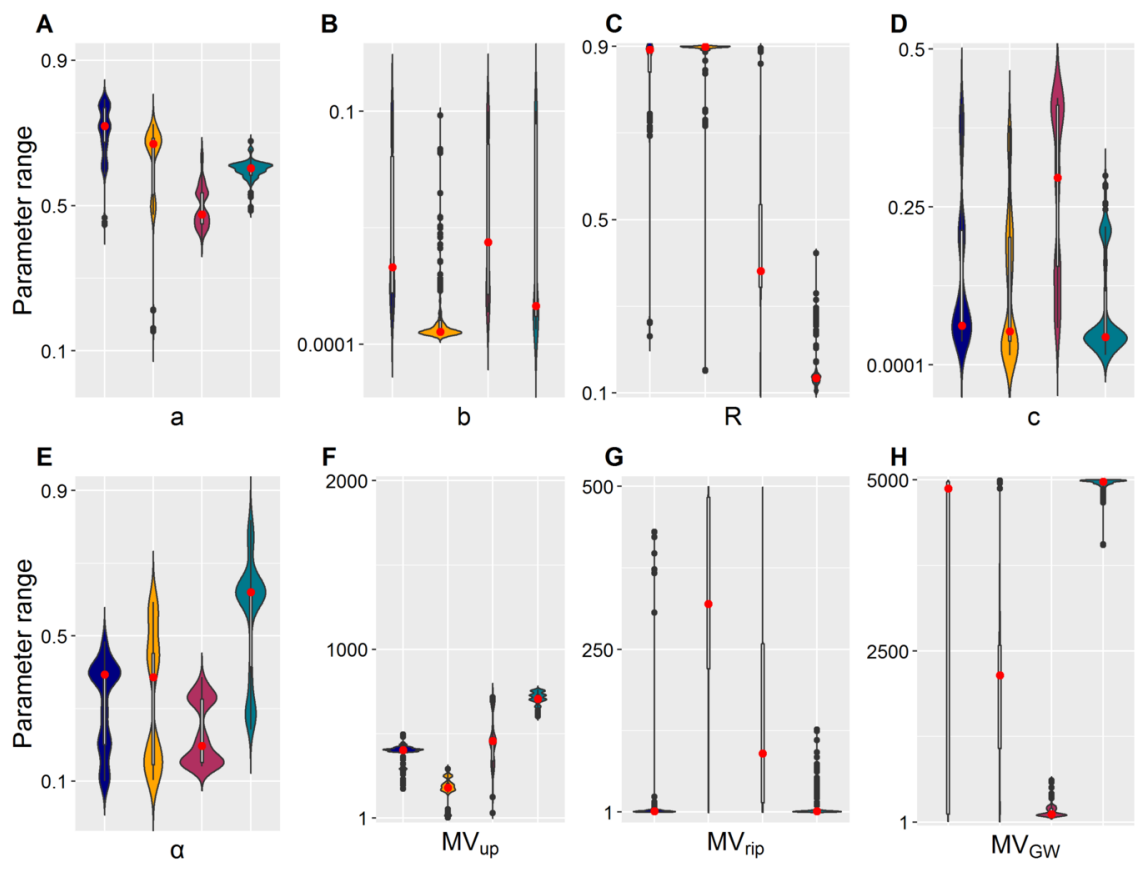

Calibration D 2017-2019 $\square 2017 \square 2018 \square 2019$ 

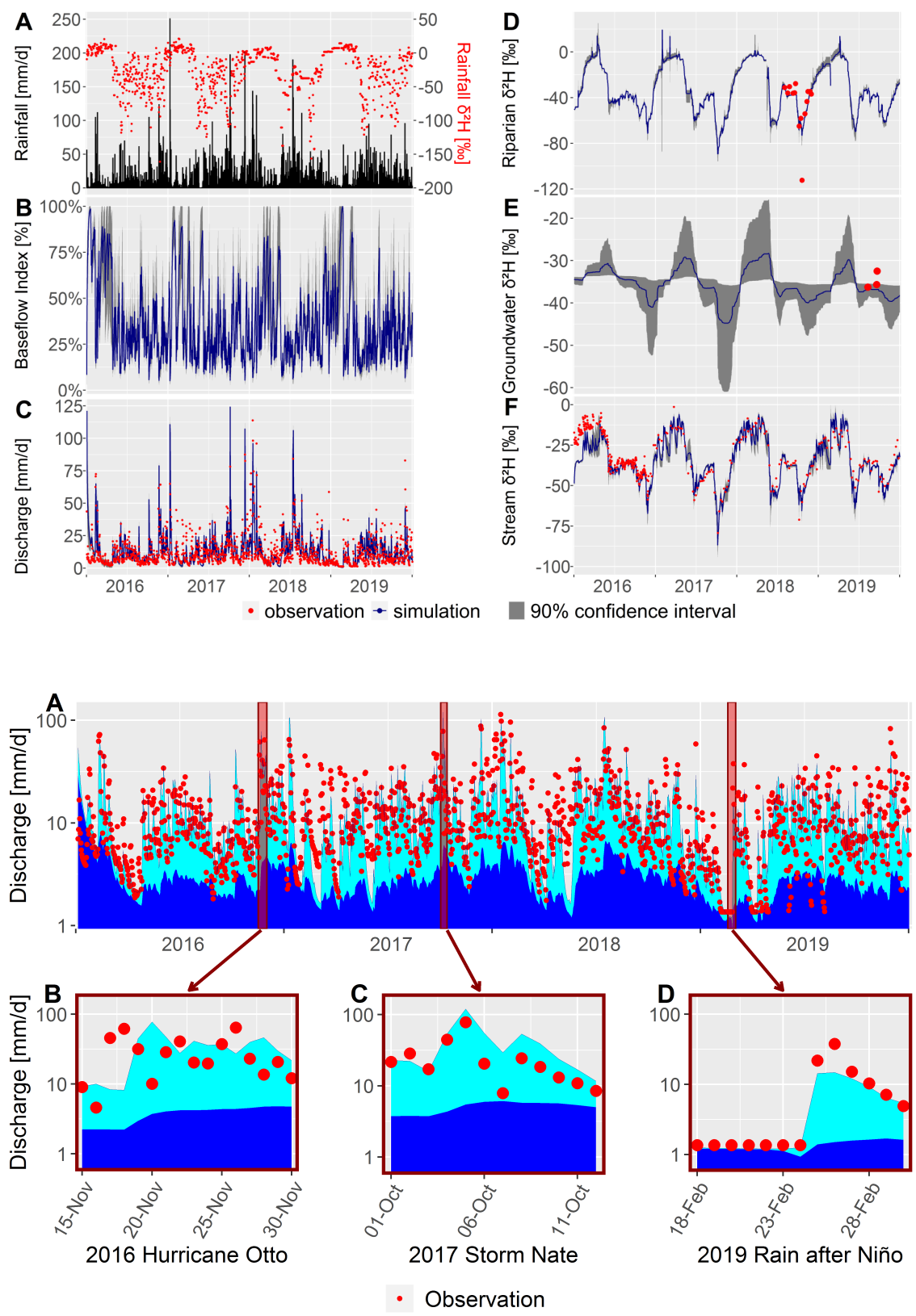

Simulation:

Surface runoff

Baseflow 


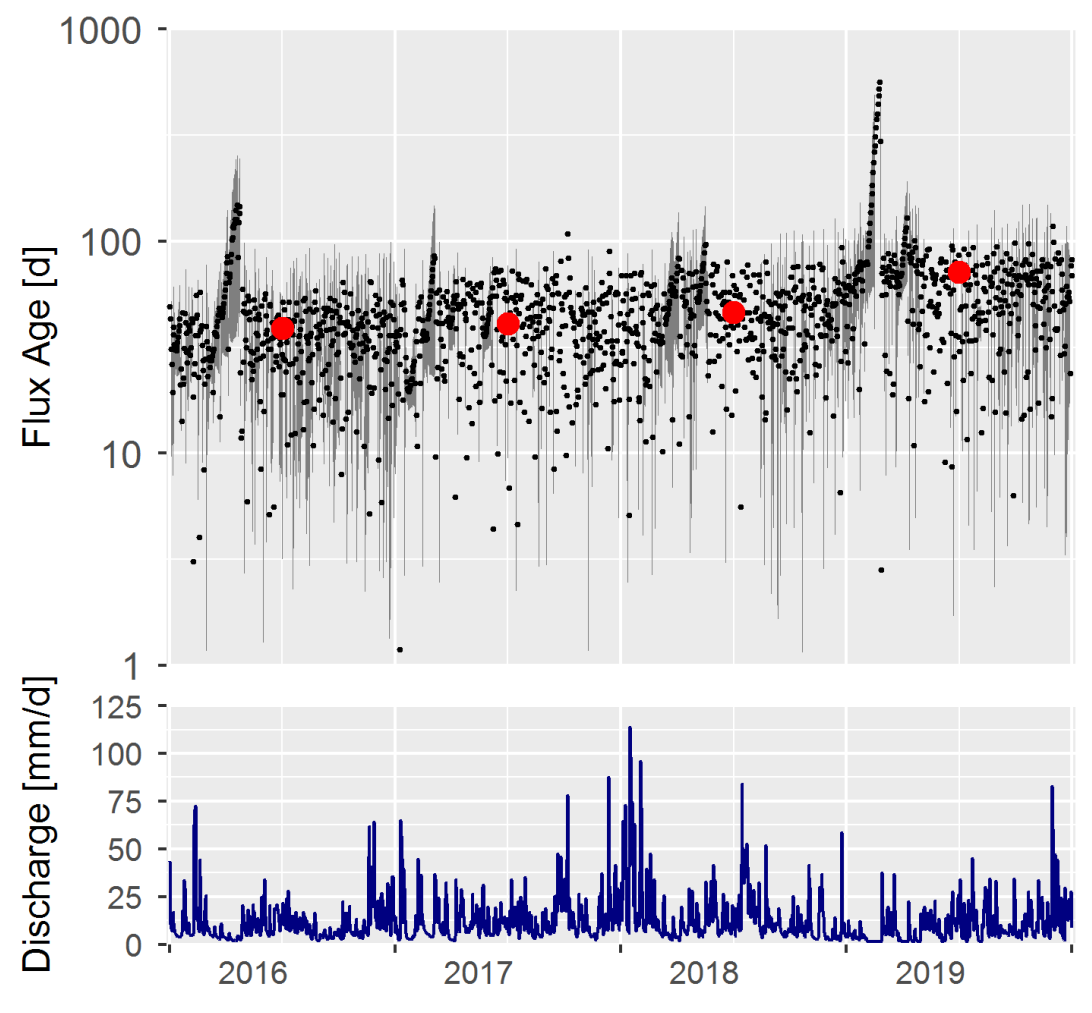

- Age - Annual Mean $68 \%$ confidence interval

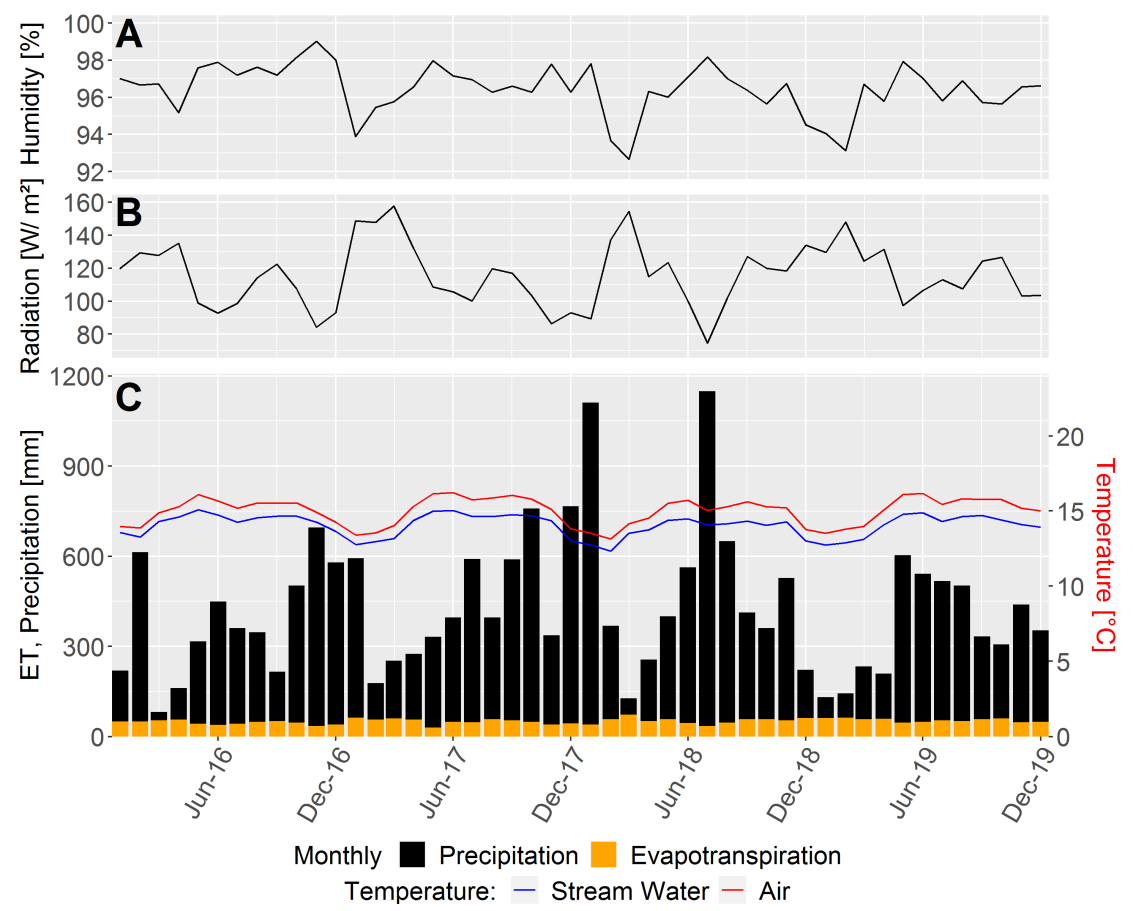

